\title{
A prospective randomized study of eTEP and TEP repair for inguinal hernia in terms of ease of operability, complication and recurrences
}

\author{
Siddharth Singh', Sanjay Kala², Jauhari R K ${ }^{3}$, Yukteshwar Mishra ${ }^{4}$, Avinash Yadav ${ }^{5}$ \\ ${ }^{1,3}$ Associate Professor, ${ }^{2}$ Professor, ${ }^{4}$ Assistant Professor, ${ }^{5}$ Postgraduate Resident, Department of Surgery, Ganesh \\ Shankar Vidyarthi Memorial Medical College, Kanpur, Uttar Pradesh, India
}

Background: Inguinal hernia is one of the diseases that has haunted humanity from its very beginning to the modern times. Groin hernias are the most common conditions referred to surgeons all over the world and over five lakh hernia repairs are performed annually. The lifetime risk for men is $27.0 \%$ and for women is $3.0 \%$. Approximately $75.0 \%$ of all abdominal wall hernias occur in the groin. Inguinal hernias are more common on the right than on the left and are seven times more likely in males than in females. Aims and Objectives: Aim and objective of the study is to compare extended total extra peritoneal (e-TEP) and total extra peritoneal (TEP) repair in terms of complications and recurrence. To evaluate ease of operability of e-TEP and TEP for inguinal hernia repair. Materials and Methods: Patients with inguinal hernia who were hospitalized to the Department of General Surgery at GSVM Medical College, Kanpur, and who were over the age of 18 years of both sexes were studied from December 2019 to October 2021 after signing a consent form. The research procedure followed was in accordance with the approved ethical standards of GSVM Medical College, Kanpur, UP, India Ethics Committee (Human). Data were analyzed and evaluated using Statistical Package for Social Sciences, version 23 (SPSS Inc., Chicago, IL). Results for continuous variables are shown as mean \pm standard deviation, whereas results for categorical variables are shown as number (percentage). For comparison of nominal data, Chi-square $\left(\chi^{2}\right)$ test was used. The level $\mathrm{P}<0.05$ was considered as the cut-off value of significance. Results: Majority of the patients of Group TEP (25 patients) had complications as Conversion to trans abdominal pre-peritoneal (TAPP) $4(16.0 \%)$ and proceed surgery without veress needle decompression $2(8.0 \%)$. In Group eTEP (25 patients) majority of patients had complications as proceed surgery without veress needle decompression 8 (32\%) followed by Seroma $2(8.0 \%)$. No recurrences seen in either groups. Mean operative time of eTEP was less as compared to TEP. Conclusion: With TEP, complications such as SSI, hematoma, and conversion to TAPP are more common; however with eTEP, proceed surgery without veress needle decompression and seroma. Considering the average operative time of eTEP and TEP, as well as the bigger defect size that eTEP can readily handle. For new surgeons, eTEP is a more straightforward procedure. Moreover, our study findings showed that e-TEP mesh repair of inguinal hernia showed more firm and efficacious results than TEP repair. We suggest that long-term randomized control trials with enhanced sample size and reduced confounding factors are still required to establish the absolute superiority of e-TEP over TEP.

Key words: Extended totally extraperitoneal repair; Inguinal hernia; Laparoscopic Inguinal hernia repair; Totally extraperitoneal repair
Access this article online

Website:

http://nepjol.info/index.php/AJMS

DOI: 10.3126/ajms.v13i3.41341

E-ISSN: 2091-0576

P-ISSN: 2467-9100

Copyright (c) 2022 Asian Journal of Medical Sciences

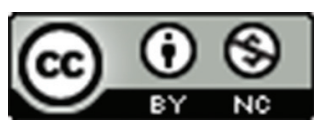

This work is licensed under a Creative Commons Attribution-NonCommercial 4.0 International License. 


\section{INTRODUCTION}

Inguinal hernial repair is one of the most frequently performed operations in general surgery. The standard method for inguinal hernial repair had changed little over 100 years until the introduction of synthetic mesh. This mesh can be placed by either using an open approach or using a minimal access laparoscopic technique. The concept of hernial repair underwent evolution from Bassini's repair to Lichtenstein tension-free repair with the introduction of polyethylene mesh.

After many years of improvement, hernioplasty is now broadly performed. The techniques which are practiced widely presently are mainly

1. Trans abdominal pre-peritoneal (TAPP)

2. Total extra peritoneal (TEP)

3. Intraperitoneal only meshplasty

4. Extended view TEP (e-TEP)

Each technique has its own applications and pitfalls and has a very gradual learning curve; hence, they have remained confined to the expert hands only. The Newer modification of TEP is e-TEP. The e-TEP technique ensures that the extra peritoneal space can be reached from almost anywhere in the anterior abdominal wall. The e-TEP approach can quickly and easily create an extra peritoneal space, enlarge the surgical field, provide a flexible port setup adaptable to many situations, allow unencumbered parietalization of the cord structures (proximal dissection of the sac and peritoneum), ease the management of the distal sac, and improve tolerance of pneumoperitoneum, which is a common complication.

\section{Aims and objectives}

1. To compare e-TEP and TEP repair in terms of complications and recurrence.

2. To evaluate ease of operability of e-TEP and TEP for inguinal hernia repair.

\section{MATERIALS AND METHODS}

The present hospital-based prospective study was conducted on patients with inguinal hernia those were admitted in Department of General Surgery at GSVM Medical College, Kanpur of age more than 18 years both sex, after obtaining the consent form the patient or their relatives were studied during the period of study from December 2019 to October 2021.

\section{Study area}

Department of General Surgery at GSVM Medical College, Kanpur.
Study duration

December 2019 to October 2021

\section{Study design}

Hospital-based prospective interventional study.

\section{Study sample}

Patients who presented with primary or incisional inguinal hernia with defect of size 4-12 cm were studied.

\section{Sample size estimation}

During the period of study a total of 50 patients were found eligible as per the inclusion criteria those were admitted to the department.

\section{Inclusion criteria}

- Age more than 18 years

- Patient giving consent for laparoscopic hernia repair

- Size of defects between 4 and $12 \mathrm{~cm}$

\section{Exclusion criteria}

- Patients with lower abdominal scar

- Patients in which laparoscopic procedure is contraindicated

- Patients with recurrence after eTEP and TEP repair

- Cases of strangulated inguinal hernia.

\section{Ethical clearance}

The research procedure followed was in accordance with the approved ethical standards of GSVM Medical College, Kanpur, UP, India Ethics Committee (Human).

\section{Statistical analysis}

Data were analyzed and evaluated using Statistical Package for Social Sciences, version 23 (SPSS Inc., Chicago, IL). Results for continuous variables are shown as mean \pm standard deviation, whereas results for categorical variables are shown as number (percentage). For comparison of nominal data, Chi-square $\left(\chi^{2}\right)$ test was used. The level $\mathrm{P}<0.05$ was considered as the cutoff value or significance.

\section{RESULTS}

In our study, total 50 patients were divided into two groups Group TEP and Group e'TEP of 25 patients each as shown in Table 1 and Figure 1

In our study, the mean age of Group TEP and Group e'TEP patients was $45.7 \pm 7.6$ and $44.2 \pm 7.4$ years, respectively; as shown in Table 2 and Figure $2 \mathrm{a}$.

In Group TEP, there were 24 males and 1 female and in Group eTEP there were 22 males and 3 were females; as shown in Figure 2b. 


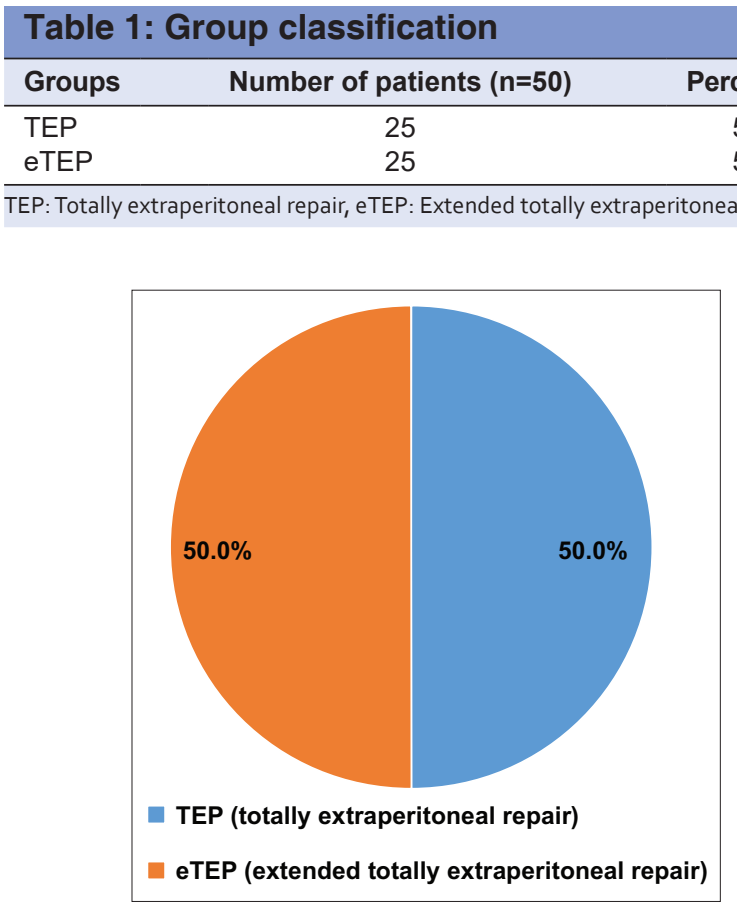

Figure 1: Group classification

Mean body mass index (BMI) calculated in Group TEP and Group eTEP was $27.4 \pm 3.8 \mathrm{~kg} / \mathrm{m}^{2}, 28.6 \pm 4.2 \mathrm{~kg} / \mathrm{m}^{2}$, respectively; as shown in Figure 2c.

Eight patients had diabetes in Group TEP and 6 patients had diabetes in Group eTEP. 10 patients had hypertension in Group TEP and 6 patients had hypertension in Group eTEP.

Age, gender, BMI, diabetes, and hypertension of the studied patients have shown non-significant correlation in both groups.

In our study, maximum primary hernia patients were found in eTEP Group $15(60 \%)$ than in TEP Group 13 (52\%). Maximum incisional hernia patients were found in TEP Group 12 (48\%) than in eTEP Group 10 (40\%); as shown in Table 3 and Figure $3 a$.

Maximum unilateral hernia patients were found in eTEP Group $22(88 \%)$ than in TEP Group $21(84 \%)$. Maximum bilateral hernia patients were found in TEP Group $4(16 \%)$ than in eTEP Group 3 (12\%); as shown in Figure 3b

Maximum right side hernia patients were found in eTEP Group $20(80 \%)$ than in TEP Group $19(76 \%)$. Maximum left side hernia patients were found in TEP Group $6(24 \%)$ than in eTEP Group 5 (20\%) as shown in Figure 3c.

Maximum indirect hernia patients were found in TEP Group $20(80 \%)$ than in eTEP Group $18(72 \%)$.

\begin{tabular}{|c|c|c|c|}
\hline Parameters & TEP $(n=25)$ & eTEP $(n=25)$ & P-value \\
\hline Mean Age & $45.7 \pm 7.6$ & $44.2 \pm 7.4$ & 0.483 \\
\hline \multicolumn{4}{|l|}{ Gender } \\
\hline Male & $24(96.0)$ & $22(88.0)$ & 0.297 \\
\hline Female & $1(4.0)$ & $3(12.0)$ & \\
\hline Mean BMI $\left(\mathrm{kg} / \mathrm{m}^{2}\right)$ & $27.4 \pm 3.8$ & $28.6 \pm 4.2$ & 0.295 \\
\hline Diabetes & $8(32.0)$ & $6(24.0)$ & 0.529 \\
\hline Hypertension & $10(40.0)$ & $7(28.0)$ & 0.370 \\
\hline
\end{tabular}

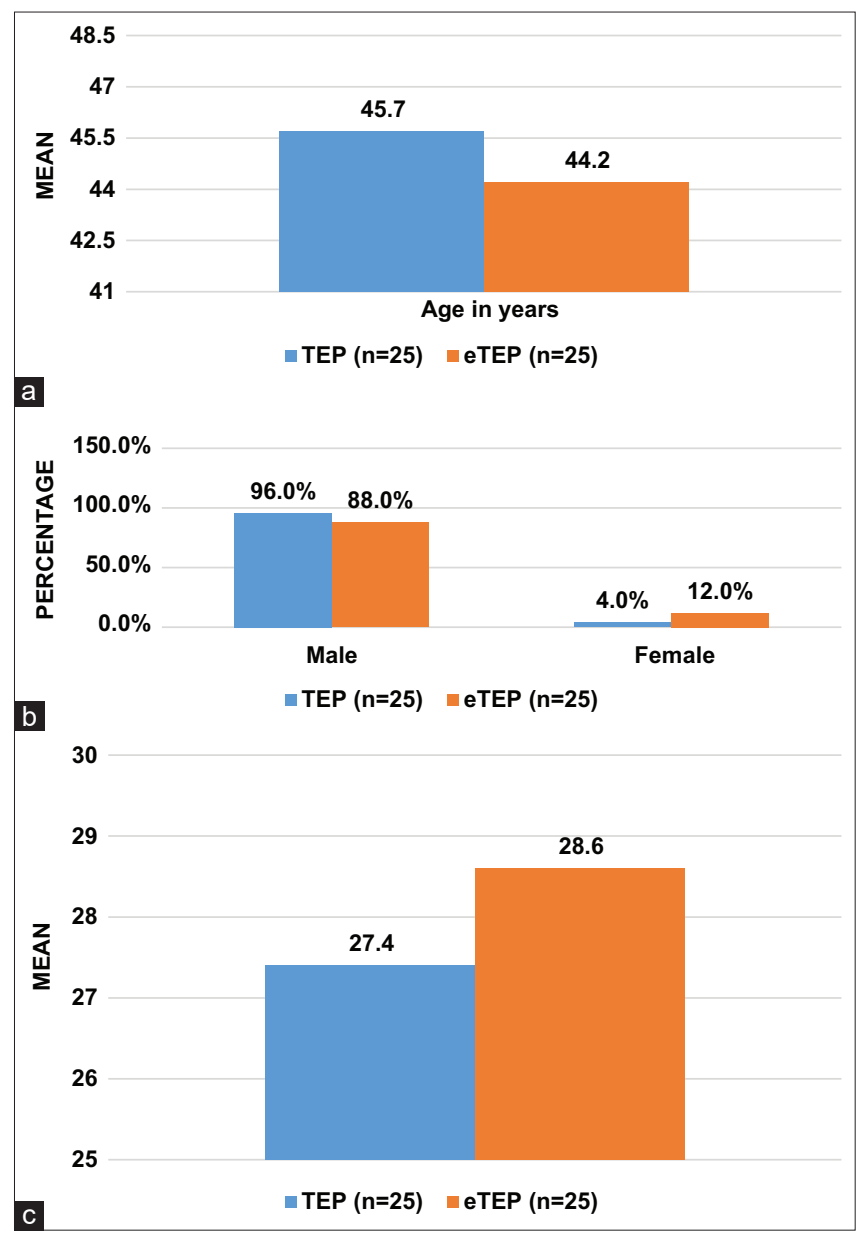

Figure 2: (a) Mean age, (b) Gender distribution, (c) Mean body mass index

Maximum direct hernia patients were found in eTEP Group $7(28 \%)$ than in TEP Group $5(20 \%)$; as shown in Figure 3d.

Mean defect size was higher in eTEP Group $(5.1 \pm 0.8)$ as

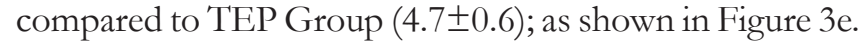

Mean size of swelling was higher in eTEP Group (23.4 \pm 17.4$)$ as compared to TEP Group (11.6 \pm 8.3$)$; as shown in Figure 3f. 
Parameters such as type of hernia, laterality, side, direct/indirect, mean defect size, and mean size of swelling among the groups showed statistically non-significant correlation.

In our study, 1 and 2 tackers were used in TEP Group as $15(60 \%)$ and $10(40 \%)$, respectively. 4, 5 and 6 tackers were used in e'TEP Group 16 (64\%), 7 (28\%) and 2 (8\%) respectively; as shown in Table 4 and Figure 4.

- Number of tackers among the groups (Group TEP,

Group e'TEP) showed significant correlation.

In our study, the mean operative time of Group TEP (167.6 \pm 32.4$)$ was higher as compared with Group eTEP (127.5 \pm 23.4$)$; as shown in Table 5 .

\begin{tabular}{|c|c|c|c|}
\hline Parameters & TEP $(n=25)$ & eTEP $(n=25)$ & P-value \\
\hline \multicolumn{4}{|l|}{ Type of Hernia } \\
\hline Primary & $13(52.0)$ & $15(60.0)$ & 0.568 \\
\hline Incisional & $12(48.0)$ & $10(40.0)$ & \\
\hline \multicolumn{4}{|l|}{ Laterality } \\
\hline Unilateral & $21(84.0)$ & $22(88.0)$ & 0.684 \\
\hline Bilateral & $4(16.0)$ & $3(12.0)$ & \\
\hline \multicolumn{4}{|l|}{ Side } \\
\hline Right & $19(76.0)$ & $20(80.0)$ & 0.732 \\
\hline Left & $6(24.0)$ & $5(20.0)$ & \\
\hline \multicolumn{4}{|l|}{ Direct or Indirect } \\
\hline Indirect & $20(80.0)$ & $18(72.0)$ & 0.508 \\
\hline Direct & $5(20.0)$ & $7(28.0)$ & \\
\hline Mean Defect Size $(\mathrm{cm})$ & $4.7 \pm 0.6$ & $5.1 \pm 0.8$ & 0.051 \\
\hline Size of swelling $\left(\mathrm{cm}^{2}\right)$ & $11.6 \pm 8.3$ & $23.4 \pm 17.4$ & 0.004 \\
\hline
\end{tabular}

- Mean post-operative parenteral analgesia required in Group TEP (21.4 \pm 5.5$)$ was higher as compared with Group e'TEP (12.3 \pm 2.5$)$.

- Mean Hospital stay after surgery in Group TEP $(1.7 \pm 0.7)$ was higher as compared with Group e'TEP $(1.1 \pm 0.3)$.

- Duration to return back to work after surgery in Group TEP (11.6 \pm 3.6$)$ was higher as compared with Group e'TEP (9.9 \pm 3.4$)$.

Mean operative time, mean post-operative parenteral analgesia required and mean hospital stay after surgery among the groups (Group TEP, Group e'TEP) showed significant correlation.

In our study, we observed that mean VAS score at 12 Hour after surgery was high in Group TEP (5.6 \pm 0.7 ) than in Group eTEP (4.5 \pm 0.6$)$; as shown in Table 6 and Figure 5.

- Mean VAS score at POD1 in TEP Group was 3.9 \pm 0.9 and in e'TEP Group it was 2.8 \pm 0.6 . Mean VAS score at POD3 in TEP Group was $1.1 \pm 0.5$ and in e'TEP Group it was $0.3 \pm 0.1$.

- Mean VAS score among the groups (Group TEP and e'TEP) showed significant correlation.

In our study, there were majority of patients of Group TEP (25 patients) had complications as conversion to TAPP $4(16.0 \%)$ and proceed surgery without veress needle decompression $2(8.0 \%)$; as shown in Table 7.

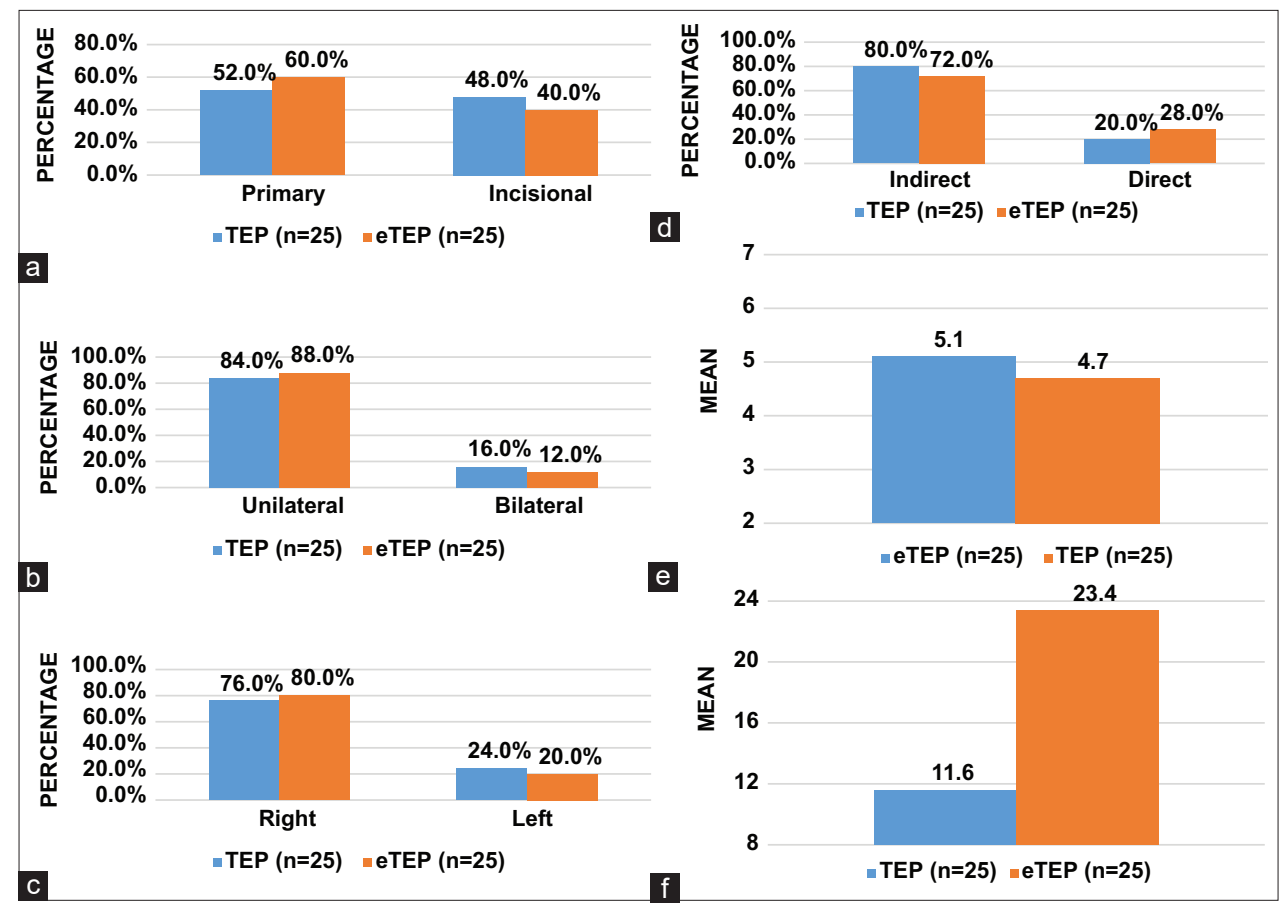

Figure 3: (a) Type of Hernia, (b) Laterality of Hernia (c) Side of Hernia, (d) Direct Indirect Hernia, (e) Mean Defect Size, (f) Size of swelling 
In Group eTEP (25 patients) majority of patients had complications as proceed surgery without veress needle decompression $8(32 \%)$ followed by Seroma $2(8.0 \%)$.

Complications like conversion to TAPP and proceed surgery without veress needle decompression among the groups showed statistically significant correlation $(\mathrm{P}<0.05)$.

\section{DISCUSSION}

Worldwide, inguinal hernia repair is one of the most common surgeries, being performed in more than 20 million people annually. ${ }^{1} \mathrm{~A}$ minority of patients is asymptomatic; however, even a watch-and-wait approach in this group results in surgery in approximately $70 \%$ within

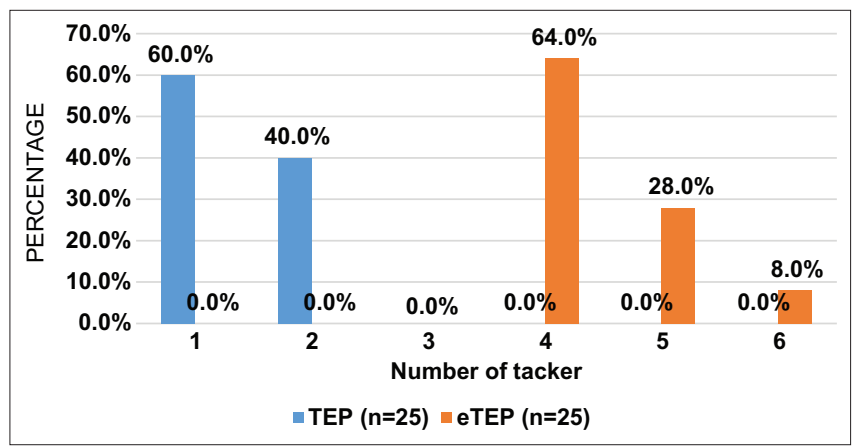

Figure 4: Number of tackers used

Table 4: Distribution of the studied patients on
the basis of number of tackers used
\begin{tabular}{lccc} 
Number of Tacker & TEP $(\mathbf{n}=\mathbf{2 5})$ & eTEP $(\mathbf{n}=\mathbf{2 5})$ & P-value \\
\hline 1 & $15(60.0)$ & 0 & $<0.001$ \\
2 & $10(40.0)$ & 0 & \\
3 & 0 & 0 & \\
4 & 0 & $16(64.0)$ & \\
5 & 0 & $7(28.0)$ & \\
6 & 0 & $2(8.0)$ &
\end{tabular}

TEP: Totally extraperitoneal repair, eTEP: Extended totally extraperitoneal repair

\begin{tabular}{|c|c|c|c|}
\hline Parameters & TEP $(n=25)$ & eTEP $(n=25)$ & P-value \\
\hline $\begin{array}{l}\text { Mean operative } \\
\text { time (min) }\end{array}$ & $167.6 \pm 32.4$ & $127.5 \pm 23.4$ & $<0.001$ \\
\hline Blood loss over $50 \mathrm{ml}$ & 0 & 0 & $>0.05$ \\
\hline $\begin{array}{l}\text { Mean post-operative } \\
\text { parenteral analgesia } \\
\text { required }(\mathrm{mg})\end{array}$ & $21.4 \pm 5.5$ & $12.3 \pm 2.5$ & $<0.001$ \\
\hline $\begin{array}{l}\text { Mean Hospital stay } \\
\text { after surgery (days) }\end{array}$ & $1.7 \pm 0.7$ & $1.1 \pm 0.3$ & $<0.001$ \\
\hline $\begin{array}{l}\text { Duration to return } \\
\text { back to work after } \\
\text { surgery (days) }\end{array}$ & $11.6 \pm 3.6$ & $9.9 \pm 3.4$ & 0.093 \\
\hline
\end{tabular}

5 years. ${ }^{2}$ Surgical treatment is successful in the majority of cases. ${ }^{1}$ The expected rate of recurrence following inguinal hernia repair is still $11 \%$ today. ${ }^{3}$ Only $57 \%$ of all inguinal hernia recurrences occurred within 10 years after the previous hernia operation. Some of the remaining 43\% of all recurrences happened only much later, even after more than 50 years.

Throughout the years there have been many advancements in the operation including the genesis of laparoscopic techniques. With a multitude of surgical methods, it can often become difficult in deciding the best method of repair. An array of factors contributes to deciding which operative technique is best utilized for a patient presenting with an inguinal hernia. We will explore these variables as well as the surgical techniques themselves. Open inguinal hernia repairs can be categorized into two main categories: tissue repair and mesh repair. There are several named techniques that can be utilized for performing a tissue repair such as the Bassini, McVay, Marcy, and Shouldice repairs. ${ }^{4}$

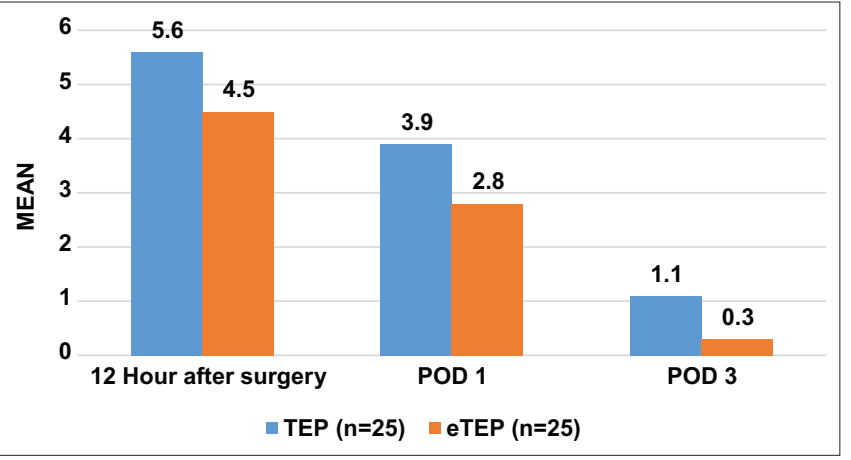

Figure 5: Post-operative pain

\begin{tabular}{|c|c|c|c|}
\hline Mean VAS Score & TEP $(n=25)$ & eTEP $(n=25)$ & P-value \\
\hline $\begin{array}{l}12 \text { Hour after } \\
\text { surgery }\end{array}$ & $5.6 \pm 0.7$ & $4.5 \pm 0.6$ & $<0.001$ \\
\hline POD 1 & $3.9 \pm 0.9$ & $2.8 \pm 0.6$ & $<0.001$ \\
\hline POD 3 & $1.1 \pm 0.5$ & $0.3 \pm 0.1$ & $<0.001$ \\
\hline
\end{tabular}

\begin{tabular}{lccc}
\multicolumn{4}{l}{ Table 7: Complications } \\
Complications & TEP $(\mathbf{n}=\mathbf{2 5})$ & eTEP $(\mathbf{n}=\mathbf{2 5})$ & P-value \\
\hline SSI & $0(0.0)$ & $0(0.0)$ & 1.00 \\
Seroma & $0(0.0)$ & $2(8.0)$ & 0.148 \\
Hematoma & $0(0.0)$ & $0(0.0)$ & 1.00 \\
Conversion to TAPP & $4(16.0)$ & $0(0.0)$ & 0.037 \\
$\begin{array}{l}\text { Proceed surgery } \\
\text { without veress needle }\end{array}$ & $2(8.0)$ & $8(32.0)$ & 0.033 \\
decompression & & & \\
Recurrence & $0(0.0)$ & $0(0.0)$ & 1.00 \\
\hline
\end{tabular}

TEP: Totally extraperitoneal repair, eTEP: Extended totally extraperitoneal repair, TAPP: Trans Abdominal Pre-Peritoneal 
eTEP is a novel technique that was first introduced by Daes in 2012 to address difficult inguinal hernias. ${ }^{5}$ The principle is to create a larger space than what is done in TEP to tackle large groin hernias. When the defect is too wide to be closed without tension, a component separation procedure is added. In general, the posterior component separation technique in the form of transversus abdominis release (TAR) as described by Dr. Novitsky et al., ${ }^{6}$ is preferred with the eTEP technique since the plane of dissection is the same. This is called eTEP TAR. It is believed that mesh placement in retromuscular space translates into vascularization of the mesh from both sides, less recurrence, fewer issues of fixation, less pain and fewer chances of bowel adhesions in addition to being economical due to the deployment of a cheaper mesh as composite mesh with anti-adhesion barrier is not needed. ${ }^{7}$ However, the technique has a steep learning curve.

Present study aims to compare eTEP and TEP repair in terms of complications and recurrence and evaluate ease of operability of eTEP and TEP for inguinal hernia repair. Study enrolled 50 patients, were divided into two groups Group TEP and Group eTEP of 25 patients each. Demographic profile was comparable for both the groups; mean age was Group eTEP patients was 45.7 and 44.2 years, respectively. Male dominance was observed in both the groups.

Baig and Priya ${ }^{8}$ reported mean age as 54.67 years and female dominance in contrast our study. Köckerling et al., ${ }^{9}$ concluded that No significant difference in mean age and BMI was found between the recurrent operations in TEP. Further, we documented the features of hernia and observed primary hernia more in eTEP group (60\%) and Incisional in TEP group (48\%). Penchev et al., ${ }^{10}$ did a study and reported that there were no differences between age, sex, BMI.

Peri-operative parameters were also logged, mean operative time of Group TEP (167.6 mins) was higher as compared with Group eTEP(127.5). In a study, they recorded mean operating time was $176.48 \mathrm{~min}$ which ranged from 138 to $310 \mathrm{~min}$ in eTEP. ${ }^{9}$ Karim et al., ${ }^{11}$ reported mean operative time for TAPP was 64.27 min, Kumar et al. ${ }^{12}$ reported operative time was significantly higher for e-TEP. Hospital stay after surgery in Group TEP $(1.7 \pm 0.7)$ was higher as compared with Group eTEP (1.1 \pm 0.3$)$ and difference among group was significant, which was in contrast to Rekhi et al., ${ }^{13}$ reported hospital stay and time to return to usual activity no statistical difference present between TEP and TAPP while pain score was in TEP more than TAPP.
Joshi et al., ${ }^{14}$ reported post-operative hospital stay was shorter in e-TEP group. VAS score among the groups (Group TEP and eTEP) showed significant correlation. VAS score at $12 \mathrm{~h}$ after surgery was high in Group TEP than in eTEP. Penchev et al., ${ }^{11}$ reported pain score from the intra-operative (the day of surgery) to the seventh post-operative day is lower in the eTEP group. Vinay and Balasubrahmany $\mathrm{a}^{15}$ reported low pain scores, similar scores were documented by Sharma et al., ${ }^{16}$ pain scores were less in Group TAPP.

In our study, there were majority of patients of Group TEP (25 patients) had complications as Conversion to TAPP 4. Complications like conversion to TAPP and proceed surgery without veress needle decompression among the groups showed statistically significant correlation. Rekhi et al., ${ }^{15}$ concluded that higher incidence of post-operative complications is associated with TAPP in comparison to TEP. In contrast Reza et al., ${ }^{17}$ reported eTEP procedure is cost effective, has minimum complication with easier learning. Hallen et al., ${ }^{18}$ reported pain was higher in the TEP, ${ }^{3}$ recurrences were found in the TEP group. Vinay and Balasubrahmanya ${ }^{18}$ concluded TEP mesh repair and TAPP mesh repair of inguinal hernia are both safe and efficacious.

\section{Limitations of the study}

Every hospital-based study has some limitations and the present study undertaken is no exception to this fact. The limitations in the present study are mentioned below,

1. The patients taken up for the study were predominantly from northern India, in and around Kanpur district. Therefore, the results of the present study may not be representative of the whole of the country or the world at large.

2. The number of patients included in the present study were less in comparison to other studies.

3. Because the trial was short, it was difficult to remark on recurrences.

\section{CONCLUSION}

1. The mean age of Group TEP and Group eTEP patients was $45.7 \pm 7.6$ and $44.2 \pm 7.4$ years, respectively.

2. In Group TEP, there were 24 males and 1 female and in Group eTEP there were 22 males and 3 were females.

3. Eight patients had diabetes in Group TEP and 6 patients had diabetes in Group eTEP. 10 patients had hypertension in Group TEP and 6 patients had hypertension in Group eTEP. 
4. Maximum primary hernia patients were found in eTEP Group $15(60 \%)$ than in TEP Group $13(52 \%)$. Maximum incisional hernia patients were found in TEP Group 12 (48\%) than in eTEP Group 10 (40\%).

5. Mean defect size was higher in eTEP Group (5.1 \pm 0.8$)$ as compared to TEP Group (4.7 \pm 0.6$)$.

6. Number of tackers among the groups (Group TEP, Group e'TEP) showed significant correlation.

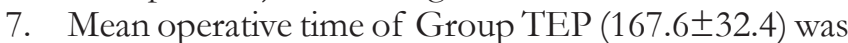
higher as compared with Group eTEP (127.5 \pm 23.4$)$.

8. Mean Hospital stay after surgery in Group TEP $(1.7 \pm 0.7)$ was higher as compared with Group e'TEP $(1.1 \pm 0.3)$.

9. VAS score at 12 Hour after surgery was high in Group TEP $(5.6 \pm 0.7)$ than in Group eTEP

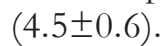

10. Majority of patients of Group TEP (25 patients) had complications as conversion to TAPP $4(16.0 \%)$ and proceed surgery without veress needle decompression 2 (8.0\%). In Group e'TEP (25 patients) majority of patients had complications as proceed surgery without veress needle decompression $8(32 \%)$ followed by Seroma $2(8.0 \%)$.

11. Considering mean operative time of e'TEP and TEP and the larger defect size easily tackled via eTEP. eTEP is easier to perform for novel surgeons.

Our study findings showed that e-TEP mesh repair of inguinal hernia showed more firm and efficacious results than TEP. We suggest that long-term randomized control trials with enhanced sample size and reduced confounding factors are still required to establish the absolute superiority of e-TEP over TEP.

\section{ACKNOWLEDGMENT}

I wish to thank Department of Surgery, Ganesh Shankar Vidyarthi Memorial Medical College, Kanpur for granting me permission to carry out the project.

\section{REFERENCES}

1. Hernia Surge Group. International guidelines for groin hernia management. Hernia. 2018;22:1-165.

https://doi.org/10.1007/s10029-017-1668-x

2. Fitzgibbons RJ, Ramanan B, Arya S, Tumer SA, Li X, Gibbs JO, et al. Long-term results of a randomized controlled trial of a nonoperative strategy (watchful waiting) for men with minimally symptomatic inguinal hernias. Ann Surg. 2013;258(3):508-515.

https://doi.org/10.1097/sla.0b013e3182a19725

3. Köckerling F, Koch A, Lorenz R, Schug-Pass C, Stechemesser B and Reinpold W. How long do we need to follow-up our hernia patients to find the real recurrence rate? Front Surg. 2015;2:24. https://doi.org/10.3389/fsurg.2015.00024
4. Ramshaw B and Chiu S. Open non-mesh inguinal hernia repair. In: La Pinska MP and Blatnik JA, editors. Surgical Principles in Inguinal Hernia Repair A Comprehensive Guide to Anatomy and Operative Techniques. Cham: Springer International Publishing; 2018. p. 33-38. https://dx.doi.org/10.1007/978-3-319-92892-0_5

5. Daes J. The enhanced view-totally extraperitoneal technique for repair of inguinal hernia. Surg Endosc. 2012;26(4):1187-1189. https://doi.org/10.1007/s00464-011-1993-6

6. Novitsky YW, Elliott $\mathrm{HL}$, Orenstein $\mathrm{SB}$ and Rosen MJ. Transversus abdominis muscle release: A novel approach to posterior component separation during complex abdominal wall reconstruction. Am J Surg. 2012;204(5):709-716.

https://doi.org/10.1016/j.amjsurg.2012.02.008

7. Binnebösel M, Klink CD, Otto J, Conze J, Jansen PL, Anurov M, et al. Impact of mesh positioning on foreign body reaction and collagenous ingrowth in a rabbit model of open incisional hernia repair. Hernia. 2010;14(1):71-77.

https://doi.org/10.1007/s10029-009-0580-4

8. Baig SJ and Priya P. Extended totally extraperitoneal repair (eTEP) for ventral hernias: Short-term results from a single centre. J Minim Access Surg. 2019;15(3):198-203.

https://doi.org/10.4103/jmas.jmas_29_18

9. Köckerling F, Bittner R, Kuthe A, Hukauf M, Mayer F, Fortelny R, et al. TEP or TAPP for recurrent inguinal hernia repairregister-based comparison of the outcome. Surg Endosc. 2017;31(10):3872-3882.

https://doi.org/10.3389/fsurg.2015.00024

10. Penchev D, Kotashev $G$ and Mutafchiyski V. Endoscopic enhanced-view totally extraperitoneal retromuscular approach for ventral hernia repair. Surg Endosc. 2019;33(11):3749-3756. https://doi.org/10.1007/s00464-019-06669-2

11. Karim T, Katiyar VK, Jain A, Patel G, Nurbhai SM and Kumar RB. Comparison of trans-abdominal preperitoneal repair with Lichtenstein tension-free hernioplasty: A prospective study. Formos J Surg. 2021;54:19-24.

https://doi.org/10.4103/fjs.fjs 8920

12. Kumar N, Palanisamy NV, Parthasarathi R, Sabnis SC, Nayak SK and Palanivelu C. A comparative prospective study of short-term outcomes of extended view totally extraperitoneal (e-TEP) repair versus laparoscopic intraperitoneal on lay mesh (IPOM) plus repair for ventral hernia. Surg Endosc. 2021;35(9):5072-5077. https://doi.org/10.1007/s00464-020-07990-x

13. Rekhi HS, Singh G, Sharma E and Goyal A. Assessment of perioperative outcome in primary unilateral inguinal hernia: A comparative study. Int J Surg Sci. 2020;4(2):229-232. https://doi.org/10.33545/surgery.2020.v4.i2d.422

14. Joshi $\mathrm{J}$ and Dekhaiya F. A Comparative study between E-TEP versus IPOM hernia repair. IOSR J Dent Med Sci. 2020;19(3):19-21. https://doi.org/10.9790/0853-1903161921

15. Vinay $G$ and Balasubrahmanya KS. Comparative study on laparoscopic transabdominal pre-peritoneal (TAPP) mesh repair and total extra-peritoneal (TEP) repair in inguinal hernia. Madridge J Surg. 2018;1(1):9-13. https://doi.org/10.18689/mjs-1000103

16. Sharma D, Yadav K, Hazrah P, Borgharia S, Lal R and Thomas S. Prospective Randomized trial comparing laparoscopic transabdominal preperitoneal (TAPP) and laparoscopic totally extra peritoneal (TEP) approach for bilateral inguinal hernias. Int J Surg 2015;22:110-117. 
https://doi.org/10.1016/j.ijsu.2015.07.713

17. Reza SM, Hoque MM, Akther SM, Rahman MM, Ahmed FU, Mamun MA, et al. Early outcomes of extended view total extraperitonial (eTEP) procedure for inguinal hernia. J Shaheed Suhrawardy Med Coll. 2019;11(2):96-100.
18. Hallen M, Bergenfelz A and Westerdahl J. Laparoscopic extraperitoneal inguinal hernia repair versus open mesh repair: Long-term follow-up of a randomized controlled trial. Surgery. 2008;143(3):313-317.

https://doi.org/10.1016/j.surg.2007.09.028

\section{Authors' Contributions:}

SS- Concept and design of the study, prepared first draft of manuscript; SK- Interpreted the results; reviewed the literature and manuscript preparation;

JRK- Concept, coordination, statistical analysis and interpretation, preparation of manuscript and revision of the manuscript; YM- Reviewed the literature and manuscript preparation; AY- Preparation and revision of the manuscript

Work attributed to:

Ganesh Shankar Vidyarthi Memorial Medical College, Kanpur - 208002, Uttar Pradesh, India

\section{ORCID ID:}

Dr. Siddharth Singh - (D) https://orcid.org/0000-0002-3262-0832

Dr. Sanjay Kala - (1) https://orcid.org/0000-0001-8669-7512

Dr. Jauhari R K - (i) https://orcid.org/0000-0003-2866-4063

Dr. Yukteshwar Mishra- (i) https://orcid.org/0000-0001-6402-4341

Dr. Avinash Yadav- (10) https://orcid.org/0000-0001-7966-5600 